\title{
Uso e ocupação do solo da microbacia do igarapé Nazaré, Ji-Paraná, Rondônia: subsídios para o enquadramento
}

\author{
Alan Gomes Mendonça $^{1 \star ~(D), ~ J o s i l e n a ~ d e ~ J e s u s ~ L a u r e a n o ~}{ }^{1}$ (D), Igor David da Costa ${ }^{2}$ (D), Daíse da Silva \\ Lopes $^{3}$ (D), Lindolaine Machado de Sousa 3 (D), Tiago de Oliveira Lima ${ }^{4}$ (D), Ana Lúcia Denardin da \\ Rosa $^{1}$ (D), Elisabete Lourdes do Nascimento ${ }^{1}$ (D)

\footnotetext{
${ }^{1}$ Mestrado Profissional em Rede Nacional em Gestão e Regulação de Recursos Hídricos, Universidade Federal de Rondônia (Campus Ji-Paraná), Rua Rio Amazonas, 351 - Jardim dos Migrantes, Ji-Paraná/RO, 76900-726.

${ }^{2}$ Mestrado Profissional em Rede Nacional em Gestão e Regulação de Recursos Hídricos - Universidade Federal Fluminense, Rua Miguel de Frias, 9, Icaraí, Niterói - RJ, 24220-900.

${ }^{3}$ Eng. Ambiental e Sanitária, Universidade Federal de Rondônia (Campus Ji-Paraná), Rua Rio Amazonas, 351 - Jardim dos Migrantes, Ji-Paraná/RO, 76900-726.

${ }^{4}$ Universidade Federal de Rondônia (Campus Ji-Paraná), Rua Rio Amazonas, 351 - Jardim dos Migrantes, Ji-Paraná/ RO, 76900-726.
} \\ *Autor para correspondência: alanjipa@gmail.com
}

Recebido em 18 de maio de 2020.

Aceito em 29 de setembro de 2020.

Publicado em 30 de setembro de 2020.

Resumo - Melhorar o gerenciamento dos recursos hídricos no Brasil é fundamental para um bom desenvolvimento social, ambiental e econômico. Assim, os instrumentos de gestão como o enquadramento dos corpos d'água visam colaborar com a manutenção da qualidade desse recurso. Visando melhorar a gestão do recurso hídrico na região Norte brasileira, objetivou-se nesse trabalho levantar informações da etapa de diagnóstico para o enquadramento do Igarapé Nazaré, localizado no Estado de Rondônia, gerando subsídios para o enquadramento. Para alcançar os objetivos aplicouse métodos indiretos de análise da paisagem a partir do processamento de imagens de sensoriamento remoto em um SIG, e também métodos diretos como visitas periódicas na microbacia. Através dos resultados, foi possível identificar o processo histórico do uso e ocupação da microbacia chegando a 2019 com 84\% do seu território antropizado, sendo seu principal uso a pecuária ocupando $69 \%$ da área. Identificou-se grandes fontes de poluição pontuais como indústrias frigorificas (5) e o crescimento da piscicultura na última década (205 sistemas identificados) que pode estar lançando grandes cargas de nutrientes através dos efluentes gerados. Em conjunto, observou-se um crescimento constante do ambiente urbano na microbacia (10,5\%/2019) durante todos os anos analisados, gerando uma maior carga de efluente doméstico sobre a bacia.

Palavras-chave: Enquadramento. Gestão de recursos hídricos. Geoprocessamento

\section{Use and land cover of the watershed of the Igarapé Nazareth, Ji-Paraná - Rondônia: Subsidies for the framework}

Abstract - Improve management of water resources in Brazil is crucial to a good social, environmental
and economic development. Thus, management instruments such as the watershed framework aim
to collaborate with maintaining the quality of this resource. To improve the management of water
resources in Brazil's northern region, this work aimed to gather information on the diagnostic step for
the framing of the Igarapé Nazaré, located in the State of Rondônia, generating subsidies for framing. 
To achieve the objectives applied methods of indirect landscape analysis from remote sensing image processing in a GIS, and also direct methods such as periodic visits in the watershed. From the results, it was possible to identify the historical process of the use and occupation of the watershed coming to 2019 with $84 \%$ of its anthropic territory, and its main use, the livestock occupying $69 \%$ of the area. It was identified as major sources of pollution the Refrigeration industries (5) and growth of fish farming in the last decade (205 systems identified) which may be throwing large loads of nutrients through the effluents. Taken together, there was a steady increase at the watershed of the urban environment (10.5\%/2019) during all years analyzed, generating a greater load of effluent on watershed.

Key Words: Framework. Water management. Geoprocessing.

\section{Uso y ocupación de la cuenca del Igarapé Nazaré, Ji-Paraná - Rondônia: subsidios para la clasificación}

Resumen - Mejorar la gestión de los recursos hídricos en Brasil es esencial para un buen desarrollo social, ambiental y económico. Por lo tanto, los instrumentos de gestión como la clasificación de los cuerpos de agua tienen como objetivo colaborar con el mantenimiento de la calidad de este recurso. Con el objetivo de mejorar la gestión de los recursos hídricos en la región norte de Brasil, en este trabajo, se recabó información de la etapa de diagnóstico para la clasificación de Igarapé Nazaré, ubicada en el Estado de Rondônia, generando subsidios para la clasificación. Para lograr los objetivos, se aplicaron métodos indirectos de análisis del paisaje a partir del procesamiento de imágenes de teledetección en un SIG, así como métodos directos como visitas periódicas a la microcuenca. A través de los resultados, fue posible identificar el proceso histórico de uso y ocupación de la cuenca que llegó a 2019 con el 84\% de su territorio antropizado, siendo su uso principal el ganado que ocupa el 69\% del área. Se han identificado las principales fuentes puntuales de contaminación, como las industrias de refrigeración (5) y el crecimiento de la piscicultura en la última década (205 sistemas identificados), que pueden estar liberando grandes cargas de nutrientes a través de los efluentes generados. Juntos, hubo un crecimiento constante del entorno urbano en la microcuenca $(10.5 \% / 2019)$ durante todos los años analizados, generando una mayor carga de efluentes domésticos sobre la cuenca.

Palabras Clave - Clasificación. Gestión de recursos hídricos. Geoprocesamiento.

\section{Introdução}

A região Norte, possui a maior reserva de água doce do país, com cerca de $68 \%$ de toda a água concentrada em seus limites (Ana 2010), porém, possui o pior índice de esgotamento sanitário em território nacional, com 10,49\% da população com acesso a esse serviço (Brasil 2018), ocorrendo diversos conflitos relacionados ao uso da água e deterioração desse recurso, evidenciando a necessidade da otimização de sua gestão.

No processo de melhoria da gestão de recursos hídricos no Brasil, através da Lei das Águas (Lei $n^{\circ} 9.433$ de 1997), foram criados os Instrumentos da Política Nacional de Recursos Hídricos (PNRH), sendo um destes instrumentos o Enquadramento dos corpos d'água. Na Resolução n 91 de 2008 no seu Art. $2^{\circ}, \$ 1^{\circ}$ é descrito que o enquadramento corresponde ao estabelecimento de objetivos de qualidade a serem alcançados através de metas progressivas intermediárias e final de 
qualidade de água. Portanto, visa estabelecer o nível qualitativo de um corpo hídrico, promovendo a manutenção da característica do uso mais restritivo em termos de qualidade, para que possa garantir água em boa condição para seus usuários.

A proposta de enquadramento de um corpo d'água, em conformidade com o Plano de Recursos Hídricos (PRH) de uma bacia hidrográfica, de acordo com a Resolução $n^{\circ} 91$ de 2008, deve conter quatro etapas, diagnóstico, prognóstico, propostas de metas relativas às alternativas de enquadramento e programa para efetivação.

A etapa de diagnóstico trabalha com o levantamento das informações a respeito do uso e ocupação do solo da bacia do corpo hídrico a ser enquadrado, identificando as cargas de fontes poluidoras difusas e pontuais, disponibilidade, demanda e condições de qualidade das águas superficiais e subterrânea, entre outros dados de caracterização do corpo d'água a ser enquadrado (Fabbro Neto e Souza 2017), ferramentas modernas de geotecnologias vem sendo utilizadas para tal finalidade.

As geotecnologias destacam-se nesse tipo de estudo e são ferramentas importantes para melhoria da gestão dos recursos hídricos (Cornelli et al. 2016, Sobral et al. 2017). Rosa (2005) define essas ferramentas como um conjunto de tecnologias para coleta, processamento, análise e oferta de informações com referências geográficas. Essa metodologia pode ser utilizada para análises de diferentes tipos de fenômenos que ocorrem no espaço, inclusive na gestão de recursos hídricos. Esta permite o emprego de diversas informações para o conhecimento, gestão e monitoramento de bacias hidrográficas de uma região (Bajjali 2018), assim sendo destaque no diagnóstico ambiental.

Visando o estabelecimento desse instrumento na região Norte do país como metodologia de gestão baseada nas ferramentas da geotecnologia, objetivou-se levantar informações da etapa de diagnóstico para o enquadramento do Igarapé Nazaré, localizado na região central do Estado de Rondônia, gerando subsídios para o enquadramento.

\section{Material e métodos}

\section{Área de estudo}

O trabalho foi desenvolvido na microbacia do Igarapé Nazaré situada entre as coordenadas,

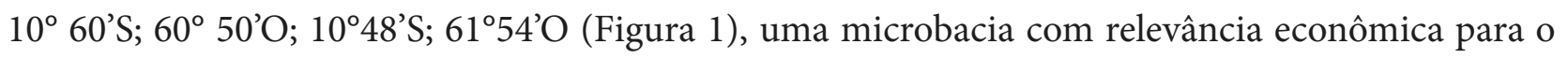
município de Ji-Paraná, região central do Estado de Rondônia, tendo em vista as diversas indústrias instaladas na região (IBGE, 2012).

A microbacia do Nazaré abrange os municípios de Presidente Médici e Ji-Paraná, sendo que sua maior parcela territorial se encontra em Ji-Paraná. Esta possui uma área de aproximadamente 107 $\mathrm{km} 2$, e as principais atividades econômicas estão associadas à agropecuária, piscicultura e indústrias frigoríficas. 
Figura 1. Localização da microbacia hidrográfica do Igarapé Nazaré no Estado de Rondônia.

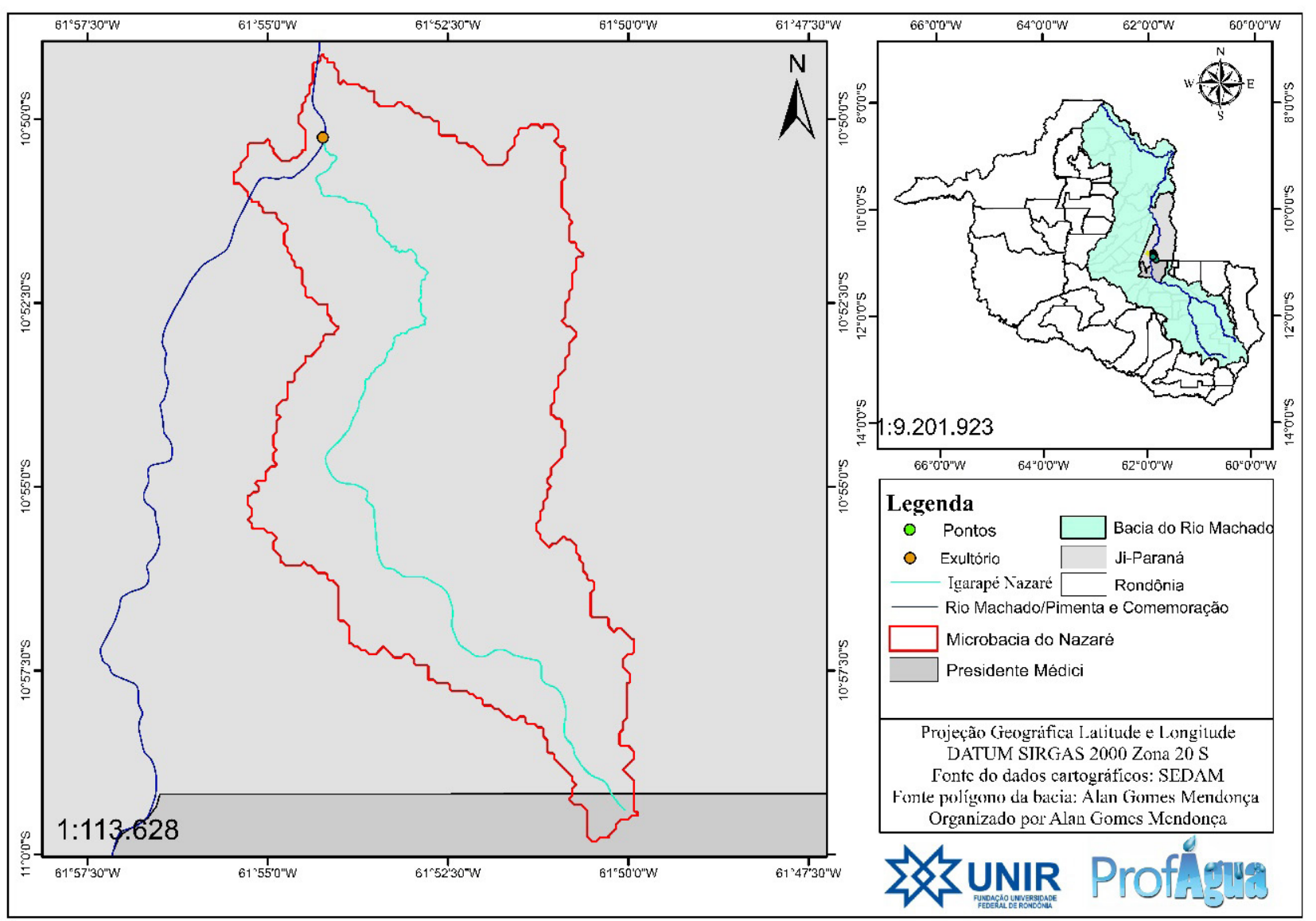

\section{Delimitação da microbacia hidrográfica}

Nessa etapa do diagnóstico ambiental da microbacia, foram utilizadas ferramentas da geotecnologia para delimitação da microbacia e análise do uso e ocupação do solo em escala multitemporal da microbacia. Realizou-se visitas a campo para reconhecimento da área, identificação de fontes de poluição (difusas e pontuais), dos usos da água, entre outras informações relevantes.

Para a delimitação da microbacia do Igarapé Nazaré foi utilizado o Softaware livre QGIS 2.18.13, utilizando um Modelo Digital de Elevação (MDE), sendo essas imagens SRTM, obtidas através da plataforma da Empresa Brasileira de Pesquisa Agropecuária (EMBRAPA), essas imagens foram processadas por preenchimento de Sinks, logo após foi obtido o fluxo de drenagem, identificado os corpos d'água e por fim delimitado a bacia.

\section{Aquisição de imagens}

A primeira fase destinou-se a obtenção de imagens do satélite Land Remote Sensing Satellite (LANDSAT), disponibilizadas gratuitamente, que foram obtidas através da plataforma do Instituto Nacional de Pesquisas Espaciais (INPE). Foram utilizadas imagens dos sensores 
Thematic Mapper (TM) e Operational Terra Imager (OLI), do LANDSAT 5 e LANDSAT 8 respectivamente.

As imagens do satélite LANDSAT foram utilizadas por serem uma das mais antigas e por serem importantes fornecedoras de dados para análise da evolução do uso e cobertura da terra do planeta (Bertucini Junior e Centeno 2016, Souza 2017), disponibilizando imagens mais antigas e de qualidade para estudo da microbacia analisada. Foram utilizadas imagens do sensor TM para os anos de 1984 (mais antiga disponível), 1994 e 2004, e para o sensor OLI, imagens dos anos de 2014 e 2019, respeitando um intervalo temporal de 10 anos até 2014.

\section{Processamento digital de imagens (PDI)}

Para realização do PDI foi utilizado o Software livre QGIS versão 2.18.13. Na primeira etapa foi realizado o registro da imagem e a determinação do sistema de projeção geográfica do projeto, que para o Brasil é o Sistema de Referência Geocêntrico para as Américas (SIRGAS).

Após as devidas correções iniciou-se a etapa de classificação das imagens, que se baseou no método de classificação supervisionado de Máxima Verossimilhança (MAXVER), que já apresentou bons resultados para análise de uso e cobertura do solo no Estado de Rondônia (Moura et al. 2017, Santos et al. 2019). Após a classificação foi convertido os dados matriciais em dados vetoriais e elaborado a álgebra de mapas e a elaboração dos mapas temáticos.

Para isto foram utilizadas 3 bandas de imagens de cada sensor para composição RGB (Tabela 1), para posterior seleção de amostras para classificação supervisionada conforme tabela:

Tabela 1. Bandas de imagens utilizadas para composição RGB.

\begin{tabular}{cccc}
\hline Sensores/Composição & R & G & B \\
\hline LANDSAT5-TM & Banda 5 & Banda 4 & Banda 3 \\
LANDSAT8-OLI & Banda 6 & Banda 5 & Banda 4 \\
\hline
\end{tabular}

Após a composição realizou-se o processo de extração de atributos para elaboração dos mapas temáticos através da classificação de imagens.

\section{Índice de vegetação da diferença normalizada (NDVI)}

O NDVI é uma técnica do sensoriamento remoto muito utilizada para indicar a presença e condição da vegetação natural ou agrícola a ser monitorada (Gamarra et al. 2016). Para elaboração do NDVI é utilizado duas bandas espectrais de imagens de satélite, sendo elas, o vermelho e o infravermelho próximo, onde o cálculo é realizado da seguinte forma:

$$
\mathrm{NDVI}=(\mathrm{NIR}-\mathrm{R}) /(\mathrm{NIR}+\mathrm{R})
$$

Onde:

NIR = Reflectância da vegetação na banda do infravermelho próximo.

$\mathrm{R}=$ Reflectância da vegetação na banda do vermelho. 
Para elaboração do NDVI da microbacia foi utilizado o Software QGIS 2.18.13 aplicando o uso de duas bandas dos satélites LANDSAT5-TM e LANDSAT8-OLI, numa escala temporal conforme o padrão análise do uso e ocupação do solo (Tabela 2).

Tabela 2. Bandas utilizadas para a elaboração do NDVI.

\begin{tabular}{ccc}
\hline Sensores/Composição & R & NIR \\
\hline LANDSAT5-TM & Banda 3 & Banda 4 \\
LANDSAT8-OLI & Banda 4 & Banda 5 \\
\hline
\end{tabular}

O NDVI é representado por valores que variam de -1 a 1 , onde os valores próximos a zero representam áreas não vegetadas, menor que zero presença de nuvens ou água, e próximo a 1 presença de vegetação densa (Lobato et al. 2010, Gamarra et al. 2016).

\section{Visitas a Campo}

Foram realizadas saídas a campo nos períodos de março, junho, setembro e dezembro de 2019, para melhor observação da área do Igarapé Nazaré. Foram coletadas coordenadas geográficas e fotos, locais de impactos pontuais e difusos de poluição do Igarapé Nazaré e seus afluentes. Realizou-se também o levantamento de indústrias, descarte irregular de resíduos, criação de gado, entre outras atividades potencialmente poluidoras na microbacia.

\section{Resultados e discussão}

\section{Análise temporal do uso e ocupação do solo}

Através da metodologia de classificação de imagens foram produzidos quatro mapas para os anos de 1984, 1994, 2004 e 2014 (Figura 2), onde apresentam os resultados da classificação das imagens em escala temporal, a respeito do uso e ocupação do solo na microbacia. 
Figura 2. Mapa da classificação do uso e ocupação do solo da microbacia do Nazaré em 1984, 1994, 2004 e 2014.

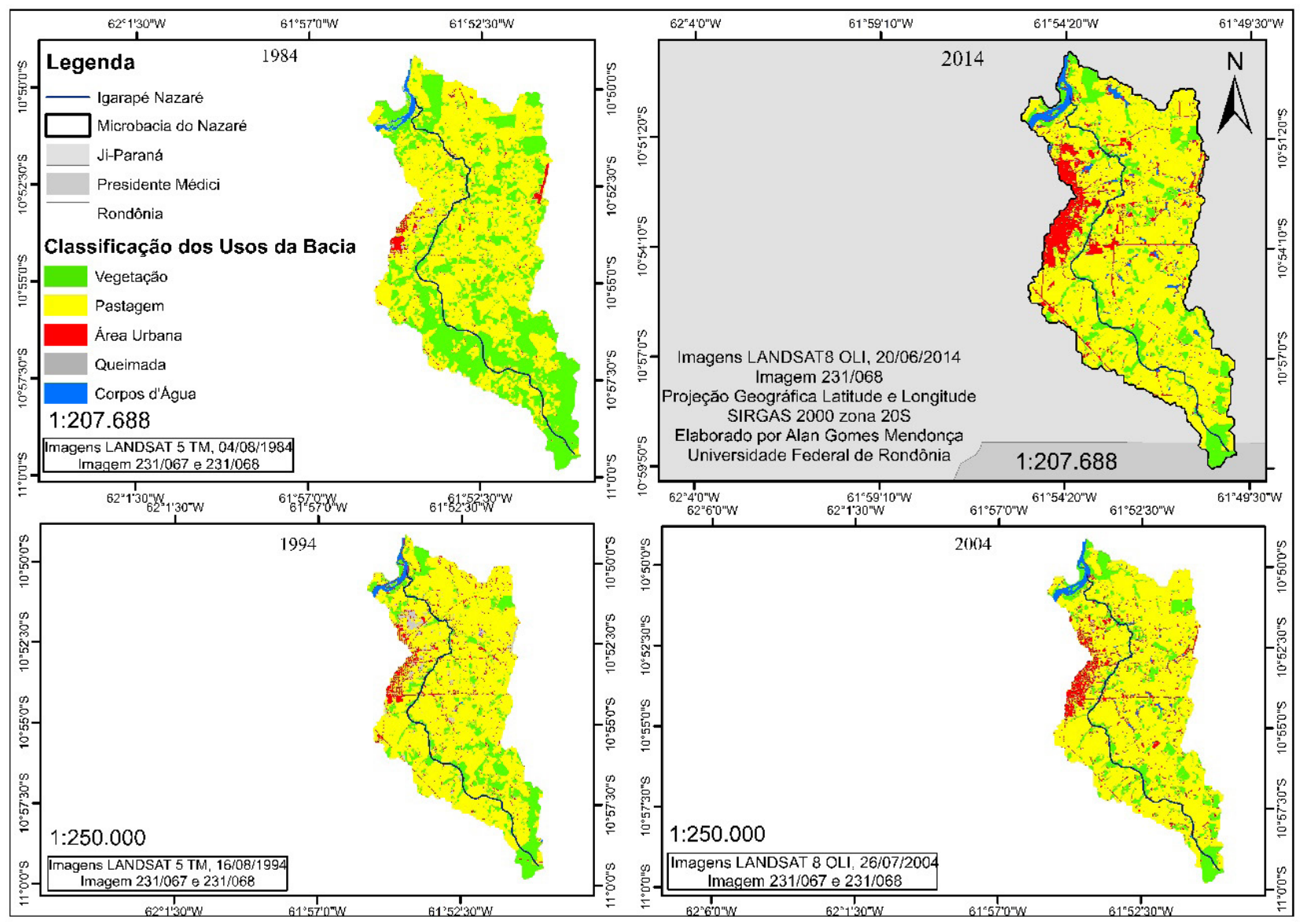

Conforme as imagens apresentadas nos mapas, observou-se que o processo de antropização da bacia já se encontrava bem acentuado no ano de 1984, tendo sua área de vegetação substituída por pastagem para criação extensiva de gado, decorrente da ocupação do território do Estado de Rondônia entre as décadas de 1970 e 1980. Estes anos corresponderam ao período mais intenso de ocupação, principalmente em razão dos planos de assentamentos realizados pelo Instituto de Colonização e Reforma Agrária (INCRA), com a formação de assentamentos para famílias e a expansão da agropecuária (CIM 2003, Fearnside 2005, Becker 2005, Paula 2008).

A Tabela 3 apresenta a evolução do uso e ocupação do solo de 1984 a 2014 na microbacia do Igarapé Nazaré.

Ao analisar a Tabela 3, nota-se que já em 1984, mais de $60 \%$ da área $\left(66,76 \mathrm{~km}^{2}\right)$ da microbacia já estava em processo avançado de antropização, o que indica que a sua hidrografia é impactada por pelo menos 30 anos. Constata-se a pressão exercida pelas atividades desenvolvidas em seu entorno, principalmente pela falta de área de preservação permanente (APP) em alguns pontos da rede hidrográfica da bacia, como observado na Figura 2. 
Tabela 3. Evolução do uso e ocupação do solo da microbacia do Igarapé Nazaré, evidenciando a área ocupada por cada classe $\left(\mathrm{Km}^{2}\right)$.

\begin{tabular}{ccccc}
\hline \multirow{2}{*}{ Uso e ocupação } & \multicolumn{4}{c}{ Evolução Temporal (Anos) } \\
\cline { 2 - 5 } & 1984 & 1994 & 2004 & 2014 \\
\hline Vegetação & 38,55 & 18,07 & 16,50 & 16,30 \\
Pastagem & 64,18 & 79,02 & 79,61 & 76,90 \\
Área Urbana & 1,99 & 5,41 & 7,74 & 9,90 \\
Corpo d'Água & 0,73 & 1,12 & 2,08 & 2,90 \\
Queimada & 0,59 & 2,41 & 0,10 & 0,18 \\
\hline Total & 106 & 106 & 106 & 106 \\
\hline
\end{tabular}

Visto que no processo de gestão do recurso hídrico, visando sua preservação, a manutenção de florestas nas áreas de preservação permanente (APP) é de extrema relevância, em que Lima (2005) afirma que as florestas são as que melhor protegem e mantém o funcionamento e a estabilidade hidrológica das microbacias, tanto em termos de regularização de vazão, quanto em qualidade da água. Autores como Araujo (2010), Arraes et al., (2012) e Nóbrega (2014) também destacam os problemas gerados pela perca de vegetação no ciclo hidrológico, na estabilidade do solo como redução de infiltração e na recarga dos aquíferos, aumento do escoamento superficial, erosão e assoreamento dos rios.

Por meio dos dados obtidos, verifica-se que o processo de antropização se estabilizou a partir do ano de 1994, em que até 2004 a nova área ocupada por vegetação natural e/ou em recuperação diminuiu pouco mais que $1,5 \mathrm{~km} 2$, e perda de área ainda menor no período de 2004 a 2014. Um dos motivos para a redução da remoção da cobertura vegetal pode estar relacionado as leis ambientais que dificultaram o processo de desmatamento, como a lei nº 9.605 de 1998 (lei dos crimes ambientais), o novo código florestal, lei $\mathrm{n}^{\circ} 12.651$ de 2012, medidas provisórias e outros decretos durante esse período.

Nos últimos 30 anos a área da microbacia foi ocupada principalmente pela pastagem $(60,6 \%$ da microbacia no ano de 1984 e 72,5\% no ano de 2014), assim como observado por Araujo et al. (2018) que identificou na bacia do Igarapé Nazaré uma maior densidade de pastagem do que em outras bacias urbanas de Ji-Paraná. Porém, com o passar dos anos houve um avanço do perímetro urbano do município de Ji-Paraná, que cresceu aproximadamente 500\% dentro da microbacia entre os anos de 1984 e 2014, acarretando novos processos de degradação ambiental para a rede hidrográfica local, principalmente o lançamento de efluentes domésticos, industriais e o descarte irregular de resíduos sólidos. Considerando que a região Norte possui o pior índice de esgotamento sanitário do país, com 10,49\% da população atendida por esse serviço (Brasil 2019) além de diversos conflitos sobre o uso da água e deterioração desse recurso, o avanço de áreas urbanas sobre a microbacia pode ser extremamente prejudicial a qualidade da água.

O avanço da área urbana dentro de uma microbacia feito sem uma gestão adequada e sem implantação dos instrumentos de planejamento dos recursos hídricos pode trazer prejuízos ao aspecto quali-quantitativo dos recursos hídricos (Fabbro Neto \& Souza 2017). Do mesmo 
modo, Rodrigues et al. (2019), identificou em estudo da microbacia do Igarapé Dois de Abril, Ji-Paraná - Rondônia, que o avanço de atividades econômicas, devido a ocupação sem breve planejamento de áreas de preservação trás agravantes ao ecossistema e exposição dessas áreas à contaminantes como graxa, óleo provenientes de postos de combustíveis, lava jatos, oficinas mecânicas, entre outros.

Outro aspecto importante a ser observado, é a grande quantidade de reservatórios de água dentro da microbacia (Figura 2), crescimento de quase $400 \%$ da área ocupada em 1984 $(0,73 \mathrm{~km} 2)$ até $2014(2,9 \mathrm{~km} 2)$, aumento observado a partir do ano 2000. Certamente um dos principais motivos para este aumento de área identificada como corpo d'água deve-se ao avanço de atividades aquícolas (piscicultura) como uma nova alternativa de atividade econômica no Estado de Rondônia (Brasil 2003). Esse tipo de atividade utiliza significativa quantidade de água e promove a geração de efluentes ricos em nutrientes o que pode comprometer a qualidade de água dos corpos receptores (Silva et al. 2013). Além disso, estudos realizados em sistemas de piscicultura no Estado de Rondônia indicam a necessidade de monitoramento dos efluentes provenientes dessa atividade devido aos riscos fornecidos a qualidade da água no Estado (Paiva 2014, Machado 2015, Meante e Dória 2018).

Observando essa característica foi levantado o número de reservatórios encontrados na microbacia através de identificação por observação de imagem de satélite, para o ano de 2019, e criação de polígonos (manualmente) para cada reservatório encontrado, obtendo um valor de 336 reservatórios distribuídos na microbacia conforme Figura 3. É possível observar no mapa que a grande maioria dos reservatórios possuem características de sistemas de piscicultura, cerca de 205 reservatórios, considerados fontes pontuais de poluição. Os outros 131 reservatórios podem ser considerados como fontes de abastecimento para indústrias, lagoas de tratamento, dessedentação animal, recreação e/ou início de implantação de um sistema de piscicultura.

Por meio de um sistema indireto de análise, foi possível observar pelas imagens cerca de 124 nascentes, a partir da qual foi possível desenhar manualmente a rede hidrográfica da microbacia do Nazaré conforme Figura 3. Analisando a imagem, observou-se a presença de represamento de algumas das nascentes, o que pode trazer impactos negativos a quantidade e qualidade da água de toda a microbacia conforme discutido por Leal et al. (2017) em seu trabalho de caracterização hidroambiental de nascentes na bacia do córrego Itanguá em São Paulo.

É importante se atentar ao estado de preservação dessas nascentes, principalmente as localizadas dentro de área urbana, haja visto que trabalhos realizados em nascentes como o de Silva et al. (2019), encontraram desconformidades referente a CONAMA 357/05 nas características físico-químicas e biológicas das águas das nascentes de microbacias amazônicas em ambientes urbanos de Ji-Paraná (Igarapé Dois de Abril e Igarapé Pintado), próximos da microbacia do Igarapé Nazaré. 
Figura 3. Mapa de localização de nascentes e reservatórios na microbacia do Nazaré.

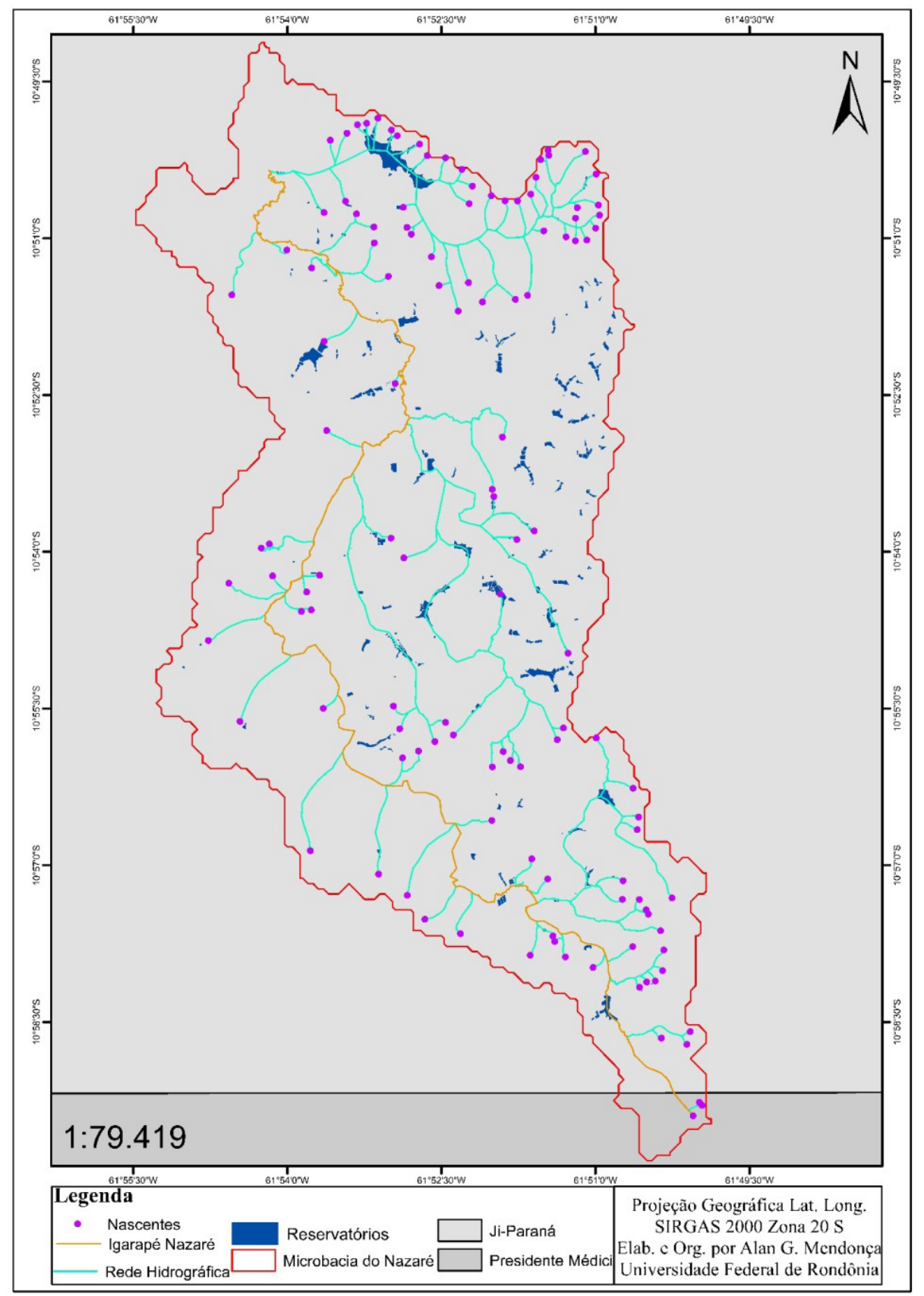

\section{Situação atual do uso e ocupação do solo da microbacia (2019)}

Conforme a análise temporal, para o ano de 2019 a microbacia manteve o padrão de evolução para os períodos anteriormente analisados, mantendo a sua área de vegetação com um pequeno crescimento (16,3 para $17,4 \mathrm{~km}^{2}$ ), acompanhado de um avanço do perímetro urbano de Ji-Paraná dentro da microbacia $\left(9,9\right.$ para $\left.11,3 \mathrm{~km}^{2}\right)$, aumento da área caracterizada por presença de água $(2,9$ para 3,18 $\mathrm{km}^{2}$ ), provável decorrência do surgimento de novos reservatórios; além de uma maior área de ocorrência de queimadas para as imagens $\left(0,18\right.$ para $\left.0,86 \mathrm{~km}^{2}\right)$, com exceção do ano de 1994 , conforme Figura 4. 
Figura 4. Mapa da classificação do uso e ocupação do solo da microbacia do Nazaré em 2019.

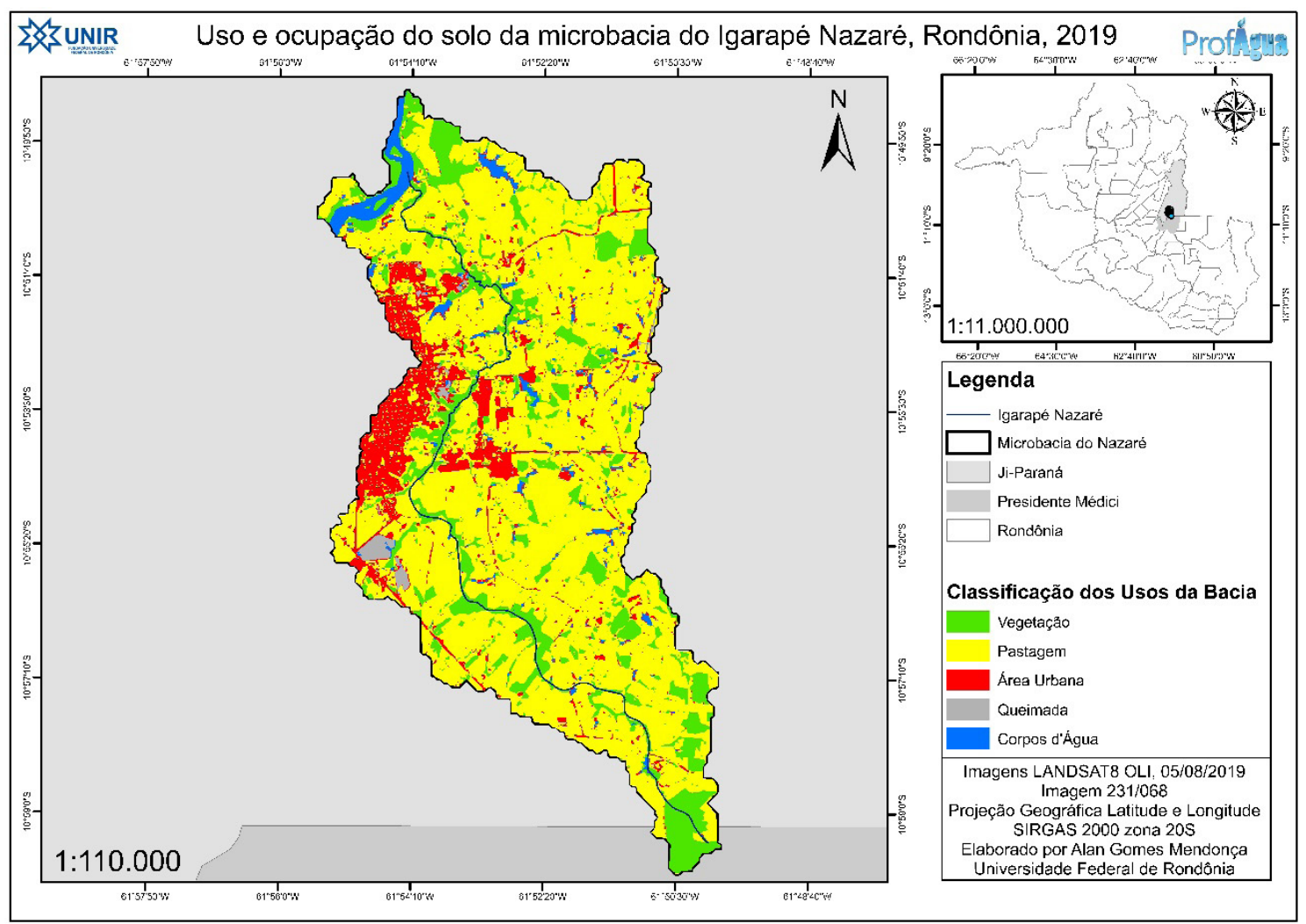

Após o processamento da imagem para o ano de 2019, os dados encontrados para a microbacia comparados com o ano de 2014 mostram nítida evolução da área urbana sobre a microbacia (pouco mais de 14\% em 5 anos, Tabela 4). Isso implementa em diferentes tipos de impactos sobre o recurso hídrico da microbacia como acumulo de lixo, assoreamento, dentre diferentes impactos que podem alterar a quantidade e a qualidade da água, afetar o ciclo hidrológico e também o microclima da região (Silva 2016, Moraes e Zacharias 2017). Visto essa condição, as observações de campo se fizeram necessárias para melhor avaliar os impactos causados por estes diferentes usos dentro da microbacia.

Tabela 4. Área ocupada por cada classe em Km2.

\begin{tabular}{ccc}
\hline \multirow{2}{*}{ Uso e ocupação } & \multicolumn{2}{c}{ Evolução temporal (Anos) } \\
\cline { 2 - 3 } & 2014 & 2019 \\
\hline Vegetação & 16,30 & 17,4 \\
Pastagem & 76,90 & 73,3 \\
Área Urbana & 9,90 & 11,3 \\
Água & 2,90 & 3,18 \\
Queimada & 0,18 & 0,86 \\
\hline Total & 106 & 106 \\
\hline
\end{tabular}




\section{Visitas a campo}

As principais fontes de poluição pontuais identificadas na microbacia do Igarapé Nazaré estão apresentadas na Figura 5. A Tabela 5 apresenta os dados de outorga de captação de água superficial e lançamento de efluentes na microbacia, obtidos através da Secretaria de Desenvolvimento Ambiental do Estado de Rondônia (SEDAM). As fontes de poluição pontuais são caracterizadas por serem de fácil localização e possuir um regime contínuo de produção, sendo assim mais simples de quantificar (Lima et al., 2016).

Figura 5. Localização das principais fontes de poluição pontual na microbacia.

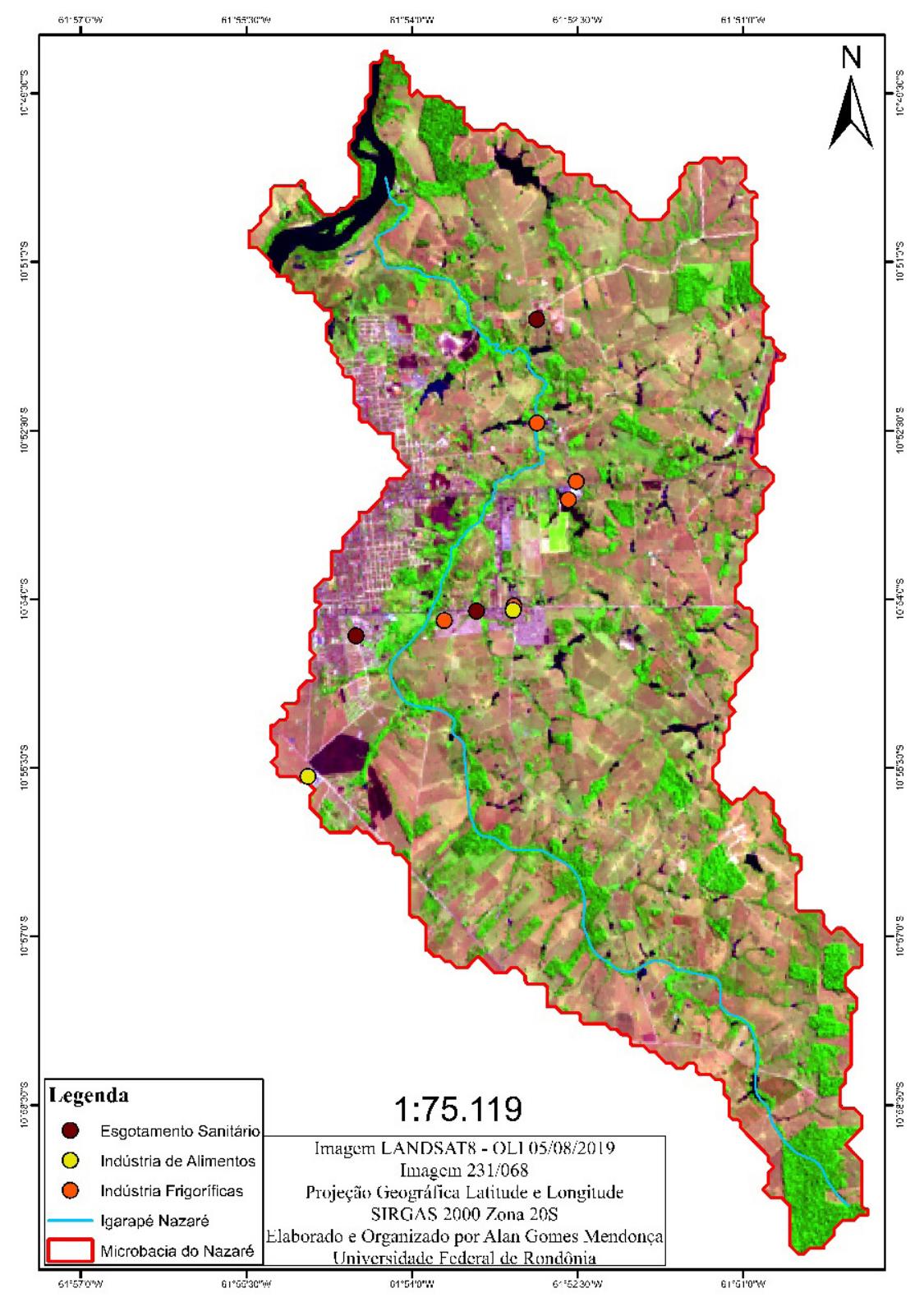

As principais fontes de poluição pontuais encontradas na microbacia estão ligadas a indústrias frigoríficas ( 5 indústrias do ramo), concentradas próximas ao perímetro urbano do município de JiParaná. Isso se deve a grande influência econômica da pecuária no Estado de Rondônia, que para o 
ano de 2018 abrigava pouco mais de 14 milhões de bovinos, ocupando o $6^{\circ}$ lugar no ranking nacional no total do rebanho (IBGE, 2018). Destaca-se também a indústria alimentícia que por produzir efluentes ricos em componentes orgânicos, materiais graxos e agentes tensoativos como dito por Furini et al. (2018) se mal tratado pode ser prejudicial a qualidade da água.

Além disso, a recente implantação de conjuntos habitacionais na microbacia são uma das principais fontes de poluição devido aos efluentes domésticos. E com avanço da área urbana traz consigo outros tipos de atividades econômicas, acarretando em geração de efluentes de diversas características assim como mencionado por Rodrigues et al. (2019), que averiguou que o processo de infraestruturação da bacia do Igarapé Dois de abril viabilizou o surgimento de empreendimentos potencialmente poluidores.

Com os dados de outorgas obtidos através da SEDAM (Tabela 5), foi possível levantar o volume de efluente outorgado para lançamento dentro da microbacia no período de 2011 a 2018, e o volume outorgado de captação de água superficial para o mesmo período. A outorga assim como o enquadramento é uma ferramenta da Política Nacional de Recursos Hídricos (PNRH), que segundo o Art. 11 da Lei 9.433 de janeiro de 1997, tem como objetivo assegurar o controle quantitativo e qualitativo dos usos da água e o efetivo exercício dos direitos de acesso à água, sendo assim um instrumento de regulação e fiscalização.

Tabela 5. Outorgas de captação de água superficial e lançamento de efluentes na microbacia do Nazaré.

\begin{tabular}{|c|c|c|c|c|}
\hline \multirow[b]{2}{*}{ Outorgante } & \multicolumn{4}{|c|}{ Usos, localização e ano de obtenção da outorga } \\
\hline & Captação & Lançamento & Coordenada & $\begin{array}{c}\text { Ano de } \\
\text { Obtenção }\end{array}$ \\
\hline $\begin{array}{c}\text { Companhia de Água } \\
\text { e Esgoto do Estado de } \\
\text { Rondônia }\end{array}$ & $1.750 \mathrm{~m}^{3} / \mathrm{h}$ & - & $\begin{array}{l}10^{\circ} 50^{\prime} 24.05^{\prime \prime} \mathrm{S} \\
61^{\circ} 54^{\prime} 12.69^{\prime \prime} \mathrm{O}\end{array}$ & 2014 \\
\hline Piscicultor & $3,05 \mathrm{~m}^{3} / \mathrm{h}$ & - & $\begin{array}{l}10^{\circ} 52^{\prime} 10,44^{\prime \prime} \mathrm{S} \\
61^{\circ} 51^{\prime} 54,25^{\prime \prime} \mathrm{O}\end{array}$ & 2011 \\
\hline Piscicultor & $35 \mathrm{~m}^{3} / \mathrm{h}$ & - & $\begin{array}{l}10^{\circ} 55^{\prime} 22.00^{\prime \prime} \mathrm{S} \\
61^{\circ} 51^{\prime} 19.00^{\prime \prime} \mathrm{O}\end{array}$ & 2017 \\
\hline Indústria Frigorífica I & - & $25 \mathrm{~m}^{3} / \mathrm{h}$ & $\begin{array}{l}10^{\circ} 52^{\prime} 26.00^{\prime \prime} \mathrm{S} \\
61^{\circ} 52^{\prime} 52.00^{\prime \prime} \mathrm{O}\end{array}$ & 2016 \\
\hline Indústria Frigorífica II & $1,60 \mathrm{~m}^{3} / \mathrm{h}$ & $40 \mathrm{~m}^{3} / \mathrm{h}$ & $\begin{array}{c}10^{\circ} 53^{\prime} 7.00^{\prime \prime} \mathrm{S} \\
61^{\circ} 52^{\prime} 35.00^{\prime \prime} \mathrm{O}\end{array}$ & 2016 \\
\hline Residencial I & $60 \mathrm{~m}^{3} / \mathrm{h}$ & $45 \mathrm{~m}^{3} / \mathrm{h}$ & $\begin{array}{c}10^{\circ} 55^{\prime} 1.78^{\prime \prime} \mathrm{S} \\
61^{\circ} 54^{\prime} 8.36^{\prime \prime} \mathrm{O} / \\
10^{\circ} 54^{\prime} 19.66^{\prime \prime} \mathrm{S} \\
61^{\circ} 54^{\prime} 30.36 \text { "O }\end{array}$ & 2018 \\
\hline Residencial II & - & $15 \mathrm{~m}^{3} / \mathrm{h}$ & $\begin{array}{c}10^{\circ} 54^{\prime} 6.46^{\prime \prime} \mathrm{S} \\
61^{\circ} 53^{\prime} 24.89^{\prime \prime} \mathrm{O}\end{array}$ & 2018 \\
\hline $\begin{array}{c}\text { Empresa de } \\
\text { Construção Civil }\end{array}$ & $30,04 \mathrm{~m}^{3} / \mathrm{h}$ & - & $\begin{array}{l}10^{\circ} 54^{\prime} 22.72 " \mathrm{~S} \\
61^{\circ} 52^{\prime} 32.09^{\prime \prime} \mathrm{O}\end{array}$ & 2013 \\
\hline Total & $129,69 \mathrm{~m}^{3} / \mathrm{h}$ & $125 \mathrm{~m}^{3} / \mathrm{h}$ & & \\
\hline
\end{tabular}


Ressalta-se que o volume oficialmente outorgado, não pode ser considerado o volume real de fontes de poluição para a microbacia do Igarapé Nazaré, tendo em vista a grande quantidade de psiculturas instaladas (Figura 3), como observado nas análises das imagens, o que dificulta a quantificação das fontes pontuais de poluição da microbacia. A necessidade na melhoria da fiscalização desse tipo de atividade deve ser implementada devido aos riscos apresentados a qualidade da água da microbacia (Paiva 2014, Machado 2015, Meante e Dória 2018), principalmente quando visado à implementação do enquadramento do corpo d'água principal da microbacia que é a base utilizada para liberação de outorgas como citado por Fabbro Neto e Souza (2017).

As fontes difusas de poluição, diferentes das pontuais, não são facilmente identificadas e quantificadas, devido a suas origens em áreas extensas e as diversas formas de transporte até os corpos d'água (Sodré 2012), destacando-se na microbacia do Igarapé Nazaré as duas principais fontes de poluição difusa, tanto de ambientes rurais como de ambientes urbanos.

Nas áreas rurais da microbacia do Igarapé Nazaré, destaca-se a pecuária, principal atividade econômica da microbacia e grande produtora de matéria orgânica decorrente dos excrementos dos bovinos ricos em nutrientes, principalmente nitrogênio, potássio, fósforo e enxofre (Mathews e Sollenbeger 1996, Haynes e Williams 1993), que com a chuva são carreados diretamente para os corpos d'água. Outra atividade ligada a pecuária e que aporta uma carga de nutriente alta aos corpos d'água, são as queimadas existentes na região norte, comumente utilizadas para limpeza de áreas e renovação de pastagem (Oliveira 2005, Mesquita 2008). Como observado na Figura 4, para a imagem analisada no ano de 2019, esse artificio se mantém em uso e pode ser extremamente prejudicial para a qualidade da água da microbacia.

Referente a área urbana, um dos principais problemas são as erosões, o aumento do escoamento superficial ao impermeabilizar o solo, a disposição de resíduos sólidos de maneira irregular. Os efluentes domésticos também podem ser enquadrados como poluição difusa, tendo em vista que no município de Ji-Paraná não existe um sistema de esgotamento sanitário eficiente, onde cerca de $77 \%$ da população não é atendida por este serviço, $4 \%$ tem seu esgoto coletado mas não tratado e pouco mais de $18 \%$ possuem soluções individuais para seu esgoto (Brasil 2018).

A inexistência de um sistema de tratamento de esgoto pode provocar um aporte de matéria orgânica elevado aos corpos d'água quando disposto incorretamente, o que pode levar ao consumo do oxigênio dissolvido na água e por consequência riscos ao ecossistema aquático (Souza 2014). A Figura 6 demonstra diferentes impactos ambientais registrados nas visitas a campo. 
Figura 6. A) presença de lixo no corpo d'água; B) erosão do solo nas margens do igarapé; C) ponto de lançamento de esgoto; D) lixo depositado a margem do igarapé; E) conversão de mata ciliar em área de pastagem; F) amostra de água coletada com características de esgoto.
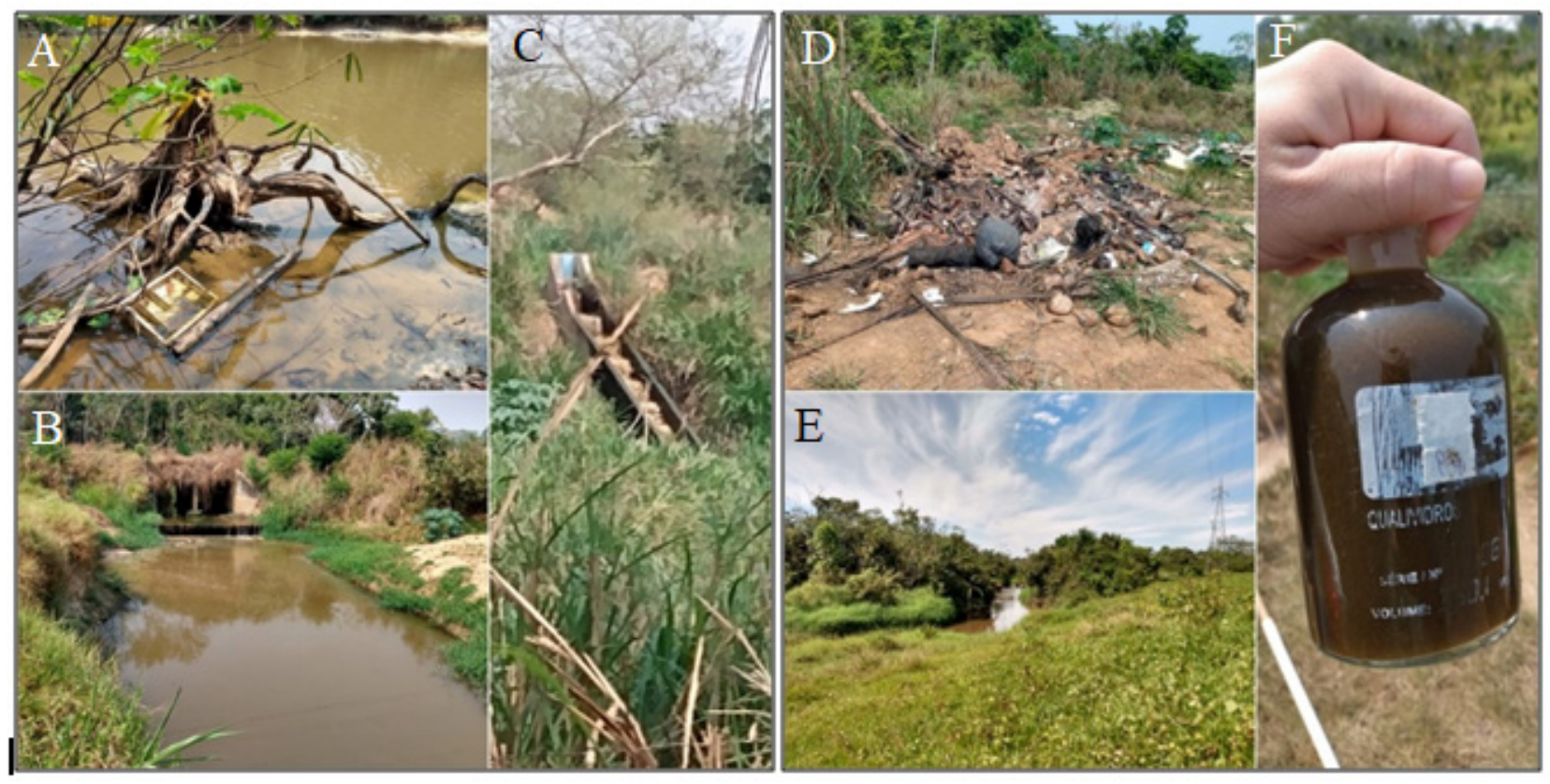

Ao analisar todas as fontes de poluição, tanto pontuais como difusas, foi constatado uma grande variedade de problemas ambientais, devido ao alto grau de antropização observado na microbacia, explicando a necessidade da implementação de instrumentos para melhoria da gestão da microbacia do Igarapé Nazaré. Enfatizando o enquadramento como uma ótima ferramenta de gestão e controle de quantidade e qualidade da água, conforme o Art. $9^{\circ}$ da lei 9.433 de 1997, onde o enquadramento visa assegurar a qualidade compatível com os usos além de diminuir os custos de combate à poluição.

A implementação desses instrumentos além da melhoria da forma de gestão, evita os processos de ocupação indesejados nas áreas de preservação, evitando danos ambientais, como o risco de inundações devido aos processos de assoreamento e a grande taxa de pluviosidade na região amazônica como discutido por Helbel et al. (2014) e Santos (2018), que em seus estudos aplicados nas bacias do Igarapé Pintado e Dois de Abril em ambiente urbano, identificaram problemas na qualidade da água dos respectivos igarapés além dos problemas recorrentes com inundações, levantando preocupações com outros igarapés que passam pelo processo de ocupação urbana como o Igarapé Nazaré.

\section{Dinâmica vegetal por NDVI}

Para avaliar a dinâmica vegetal da microbacia foi utilizado o índice de vegetação por diferença normalizada (NDVI), visto que essa análise colabora para conscientização das consequências ambientais causadas pela degradação dos recursos hídricos (Santos e Oliveira 2015). O NDVI permite identificar a presença de vegetação verde e caracterizar sua distribuição espacial, e sua evolução através dos anos, além de colaborar com o planejamento e gestão de áreas urbanas e rurais (Rosenback et al. 2005, Lobato et al. 2010). Nesse sentido, foi realizado o NDVI para os anos de 1994 e 2019 da microbacia do Nazaré, conforme apresentado na Figura 7. Foi utilizado o ano de 1994 por 
ser o ano com o maior pico de antropização da bacia se comparado aos anos de 1984, e pelo período de 1994-2004 apresentar pouca alteração na vegetação natural.

Figura 7. NDVI da microbacia do Nazaré para os anos de 1994 e 2019.

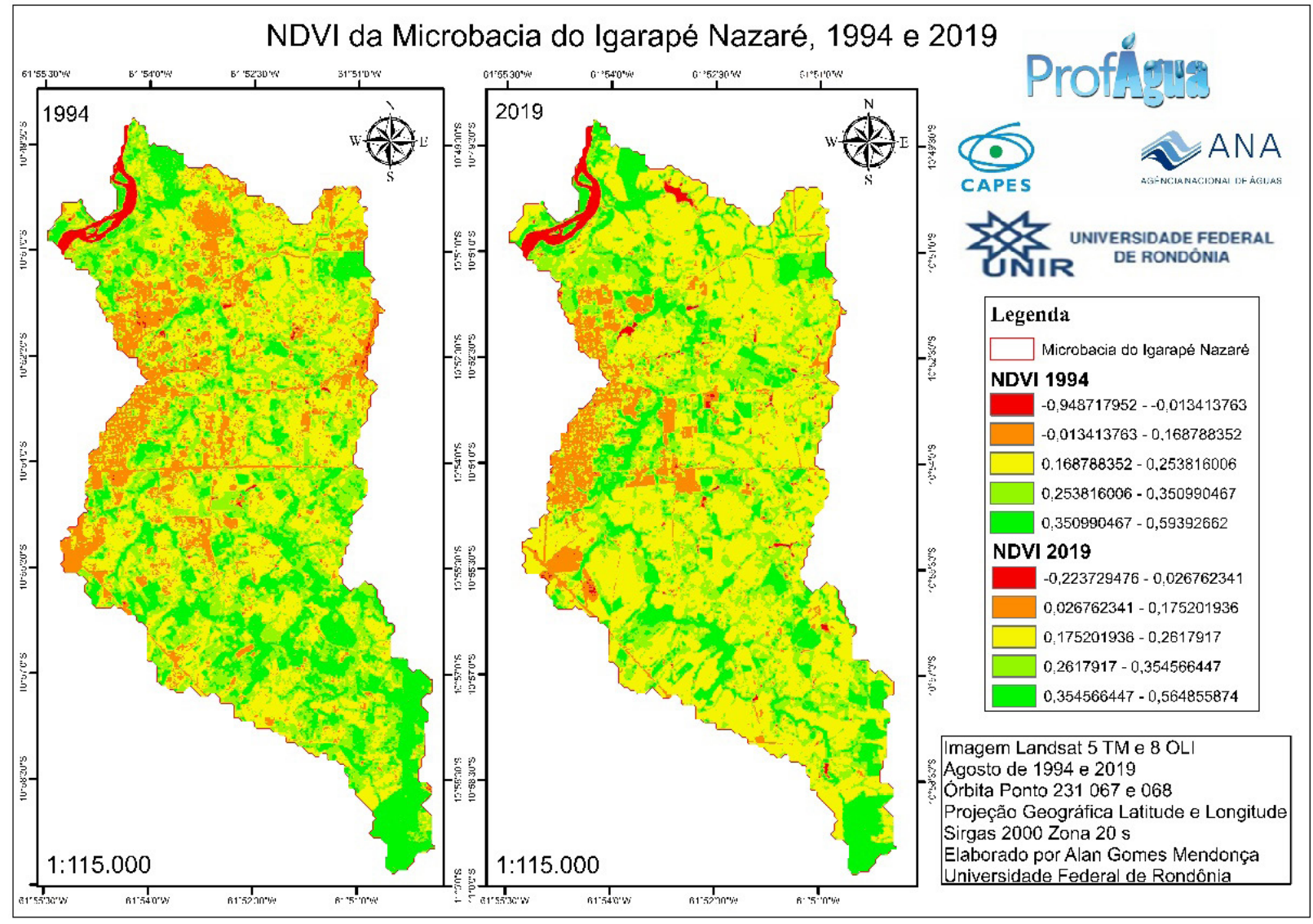

Os valores médios de NDVI foram de 0,341 e 0,338 (1994 e 2019), o que indica uma baixa redução da camada vegetal nesse período, conforme observado por Assis et al. (2017). Porém ao se observar o mapa (Figura 7), verifica-se uma área maior ocupada por presença de vegetação no ano de 1994, do mesmo modo, a área ocupada por solo exposto é maior se comparado ao ano de 2019, o que explica a pequena variação de presença de vegetação para a microbacia do Igarapé Nazaré. Isso se deve, ao observarmos a evolução do uso e ocupação do solo, pelo processo de ocupação ocorrido densamente nas décadas de 80 e 90 com remoção da camada florestal para implantação de pastagem, o que explica essa maior área de solo exposto para o ano de 1994.

Para o ano de 2019 foi constatado uma área urbana bem delimitada como a de menor reflectância $(0,028-0,17)$, e as áreas destinadas a pecuária já estabilizadas com pastos, diferenciando assim do ano de $1994(-0,013-0,16)$.

Assim, através do NDVI, pode-se afirmar que a microbacia tem seu uso bem definido, onde a atividade econômica principal se encontra estabelecida, e o ambiente urbano presente em seus limites encontra-se bem definido e em constante expansão. No entanto, como abordado por Santos \& Oliveira (2015), tal fato pode ser prejudicial à quantidade e à qualidade da água da microbacia. 


\section{Conclusão}

Ao se aplicar ferramentas do geoprocessamento para o diagnóstico ambiental de microbacias auxiliado com observações de campo, como realizado no presente estudo, foi possível levantar inúmeras informações a respeito do avanço do uso e ocupação desenvolvidos nessas áreas, caracterizando historicamente o processo de antropização e os diferentes tipos de impactos gerados.

A observação de campo permitiu identificar o impacto gerado através dos efluentes industriais dentro da microbacia, além da falta de infraestrutura urbana no município de Ji-Paraná, extremamente prejudicial aos recursos hídricos. A observação in loco dessas informações, juntamente com as análises espaciais e temporais, permitiu a elaboração de um diagnóstico completo a respeito da situação ambiental da microbacia do Igarapé Nazaré.

E esse estudo permitiu identificar que a microbacia se encontra amplamente antropizada e com um processo de degradação ambiental elevado, assim, a implementação de instrumentos que melhore a gestão do recurso se faz extremamente necessária, sendo recomendado o enquadramento desse igarapé.

\section{Agradecimentos}

O presente trabalho foi realizado com apoio da Coordenação de Aperfeiçoamento de Pessoal Nível Superior - Brasil (CAPES) - Código de Financiamento 001, agradecemos também ao Programa de Mestrado Profissional em Rede Nacional em Gestão e Regulação de Recursos Hídricos - ProfÁgua, Projeto CAPES/ANA AUXPE No. 2717/2015, pelo apoio técnico científico aportado até o momento.

Participação dos autores: AGM - desenvolvimento do projeto, coleta e análise de dados, redação do manuscrito; JJL - coleta e análise de dados; IDC- desenvolvimento do projeto, análise de dados e revisão do manuscrito, orientador do trabalho; ALDR, ELN - desenvolvimento do projeto, coleta de dados e revisão do manuscrito, orientador do trabalho; DSL, TOL - coleta e análise dos dados.

Aprovação ética e licenças: trabalho dispensado de licenças e aprovação pelo comitê de ética.

Disponibilidade dos dados: Os dados cartográficos produzidos nesse trabalho, como shapefiles da bacia hidrográfica, reservatórios, rede hidrográfica, dentre outros ficarão disponível nos sites ligados ao Grupo de Pesquisa em Águas Superficiais e Subterrâneas da Universidade Federal de Rondônia (www.gpeass.uir.br).

Fomento: bolsa concedida pela Coordenação de Aperfeiçoamento de Pessoal de Nível Superior - Brasil (CAPES) Código de Financiamento 001.

Conflito de Interesses: Não há conflito de interesses.

\section{Referências}

Agência Nacional de Águas (Brasil). 2010. Conjuntura dos recursos hídricos no Brasil: 2010 / Agência Nacional de Águas. Brasília: ANA, 2010. 76p.: li.

Agência Nacional de Águas (Brasil). 2017. Atlas Esgotos: Despoluição de Bacias Hidrográficas. Disponível em http:// atlasesgotos.ana.gov.br/ <Acesso em abril de 2020> 
Araujo RC. 2010. Efeitos do Desmatamento Sobre o Ciclo Hidrológico: uma comparação entre a Bacia do Rio Curua-Una e a Bacia do Rio Uraim. 124 f. Tese (Doutorado) - Curso de Desenvolvimento Sustentável, Universidade Federal do Pará, Belém, 2010. Disponível em: <http://repositorio.ufpa.br/jspui/bitstream/2011/11108/1/Tese_ EfeitosDesmatamentoSobre.pdf>. Acesso em: 18 out. 2019.

Araujo RR, Andrade NLR, Ribeiro JGS. 2018. Uso e Ocupação do Solo em Áreas de Preservação Permanente do Município de Ji-Paraná-RO. In: Congresso Brasileiro de Gestão Ambiental, 9., 2018, São Bernardo do Campo. IX Congresso Brasileiro de Gestão Ambiental. São Bernardo do Campo: Ibeas, p. 1-6. Disponível em: https://www.ibeas. org.br/congresso/Trabalhos2018/VIII-030.pdf. Acesso em: 6 abr. 2020.

Arraes RA, Mariano FZ, Simonassi AG. 2012. Causas do desmatamento no Brasil e seu ordenamento no contexto mundial. Revista de Economia e Sociologia Rural, Brasília, v. 50, n. 1, p.119-140. http://dx.doi.org/10.1590/s010320032012000100007.

Assis FRV, Lima JR, Silva JER, Mendonça IFC. 2017. Índice de vulnerabilidade ambiental na microbacia do Talhado, Santa Luzia, Paraíba. Acta Brasiliensis, [s.l.], v. 1, n. 3, p.8-16. http://dx.doi.org/10.22571/actabra13201747.

Bajjali W. 2018. ArcGIS for Environmental and Water Issues. Springer. 363 f.

Becker BK. 2005. Geopolítica da Amazônia. Estudos Avançados, Rio de Janeiro, v. 19, n. 53, p.71-86.

Bertucini Junior JJ, Centeno JAS. Registro de Série de Imagens LANDSAT Usando Correlação e Análise de Relação Espacial. 2016. Boletim de Ciências Geodésicas, Curitiba, v. 22, n. 4, p.685-702. http://dx.doi.org/10.1590/s198221702016000400039.

Brasil, 1997. Lei $n^{\circ}$ 9433, de 8 de janeiro de 1997. Institui a Política Nacional de Recursos Hídricos, cria o Sistema Nacional de Gerenciamento de Recursos Hídricos, regulamenta o inciso XIX do art. 21 da Constituição Federal, e altera o art. $1^{\circ}$ da Lei no 8.001, de 13 de março de 1990, que modificou a Lei n 7.990, de 28 de dezembro de 1989.. da Política Nacional de Recursos Hídricos. Brasília, DF.

Brasil. 2019. Ministério do Desenvolvimento Regional. Secretaria Nacional de Saneamento - SNS. Sistema Nacional de Informações sobre Saneamento: 24º Diagnóstico dos Serviços de Água e Esgotos. Brasília: SNS/MDR. 180 p.: il.

Brasil. 2008. Resolução no 91, de 5 de novembro de 2008. Dispõe sobre procedimentos gerais para o enquadramento dos corpos de água superficiais e subterrâneos. Brasilia, DF.

Brasil. 2003. Valdeneide de Melo Parente. Superintendência da Zona Franca de Manaus (Coor.). Projeto Potencialidades Regionais Estudos de Viabilidade Econômica: Psicultura. Manaus: Fundação Getúlio Vargas. 72 p. Disponível em: <http://www.suframa.gov.br/suframa_publicacoes_projpotregionais.cfm>. Acesso em: 17 out. 2019.

Cim S. 2013. O Processo Migratório de Ocupação no Estado de Rondônia - Visão Histórica. Primeira Versão, Porto Velho, v. 12, n. 104, p.1-12.

Cornelli R, Schneider VE, Bortolin TA, Cemin G, Santos GM. 2016. Análise da influência do uso e ocupação do solo na qualidade da água de duas sub-bacias hidrográficas do município de Caxias do Sul. Scientia Cum Industria, [s.l.], v. 4, n. 1, p. 1-14. http://dx.doi.org/10.18226/23185279.v4iss1p1.

Fabbro Neto F, Souza, MP. 2017. Leitura integrada da gestão dos recursos hídricos com o uso do solo em Caraguatatuba (SP). Engenharia Sanitaria e Ambiental, [s.l.], v. 22, n. 5, p. 853-862. http://dx.doi.org/10.1590/s1413-41522017154955.

Fearnside PM. 2005. Desmatamento na Amazônia brasileira: história, índices e conseqüências. Mega Diversidade, v. 1, n. 1, p.114-123.

Furini, LS, Genta AF, Pinheiro KLM, Lana LCO. 2018. Avaliação da estação de tratamento de efluentes industriais de uma indústria alimentícia em Contagem - MG. In: 15 $^{\circ}$ Congresso Nacional de Meio Ambiente. Poços de Caldas: If, 2018. p. 1-5. Disponível em: http://www.meioambientepocos.com.br/anais2018.html. 
Gamarra RM, Teixeira-Gamarra MC, Carrijo MGG, Filho ACP. 2016. Uso do NDVI na análise da estrutura da vegetação e efetividade da proteção de unidade de conservação no cerrado. Ra'e Ga, Curitiba, v.37, p. 307- 332. http://dx.doi. org/10.5380/raega.v37i0.42454

Haynes RJ, Williams PH. 1993. Nutrient cycling and soil fertility in the grazed pasture ecosystem. Advanced Agronomy, v.49, n.1, p.119-199.

Helbel AF, Nunes MLA, Marchetto M. 2014. Determinação de áreas sujeitas à inundação do Igarapé Pintado em JiParaná - Rondônia utilizando geotecnologias e caracterização morfométrica. Vetor, Rio Grande, v. 24, n. 2, p. 111-126. Disponível em: https://periodicos.furg.br/vetor/issue/view/534.

IBGE (Instituto Brasileiro de Geografi a e Estatística). 2017. Censo Agropecuário, Florestal e Aquícola, 2017. Pecuária. Disponível em: <https://censoagro2017.ibge.gov.br/templates/censo_agro/resultadosagro/pecuaria. html?tema=75652\&localidade=11>. Acesso em: 28 out. 2019.

Leal MS, Tonello KC, Dias HCT, Mingoti R. 2017. Caracterização hidroambiental de nascentes. Ambiente e Agua - An Interdisciplinary Journal Of Applied Science, [s.l.], v. 12, n. 1, p. 146-155, 1. Instituto de Pesquisas Ambientais em Bacias Hidrograficas (IPABHi). http://dx.doi.org/10.4136/ambi-agua.1909.

Lima PL. 2005. Floresta natural protege e estabiliza recursos hídricos. Visão Agrícola. v. 1 n. 4, p.30-33.

Lima RNS, Ribeiro CBM, Barbosa CCF, Rotunno Filho OC. 2016. Estudo da poluição pontual e difusa na bacia de contribuição do reservatório da usina hidrelétrica de Funil utilizando modelagem espacialmente distribuída em Sistema de Informação Geográfica. Engenharia Sanitaria e Ambiental, [s.l.], v. 21, n. 1, p.139-150. http://dx.doi.org/10.1590/ s1413-41520201600100127676.

Lobato R, Menezes J, Lima LA, Sapienza JA. 2010. Índice de vegetação por diferença normalizada para análise da redução da mata atlântica na região costeira do distrito de Tamoios - Cabo Frio/RJ. Caderno de Estudos Geoambientais, v.01, n.01, p.14-22. Disponível em: <http://www.cadegeo.uff.br/index.php/cadegeo/article/view/2/2>.

Machado AT. Sustentabilidade Ambiental de um Sistema de Produção de Peixes no Município de Rolim de Moura - Rondônia. 2015. 78 f. TCC (Graduação) - Curso de Engenharia de Produção, Engenharia de Produção, Universidade Federal de Rondônia, Cacoal. Disponível em: <http://www.ri.unir.br/jspui/bitstream/123456789/546/1/Monografia\%20 -\%20Alexandre\%20Tavares\%20Machado.pdf>. Acesso em: 17 out. 2019.

Mathews BW, Sollenberger LE. 1996. Grazing systems and spatial distribution of nutrients in pastures: soil considerations. In: Nutrient Cyclingin Forage Systems. 1996, Columbia, Proceedings... Joost, R. E. and Roberts, C. A. (eds.). Columbia: University of Missouri, p. 213-229.

Meante REX, Dória CRC. 2018. Caracterização da Cadeia Produtiva da Piscicultura no Estado de Rondônia: Desenvolvimento e Fatores Limitantes. Revista de Administração e Negócios da Amazônia, [s.1.], v. 9, n. 4, p.164-181. http://dx.doi.org/10.18361/2176-8366/rara.v9n4p164-181.

Mesquita AGG. 2008. Impactos das Queimadas Sobre o Ambiente e a Biodiversidade Acreana. Ramal de Ideias, Rio Branco, v. 1, p.1-14.

Moraes WR, Zacharias AA. 2017. Expansão urbana e a ocupação da microbacia do Córrego Águas da Veada - Ourinhos/ SP). Os Desafios da Geografia Física na Fronteira do Conhecimento, Campinas, v. 1, n. 1, p.784-794. http://dx.doi. org/10.20396/sbgfa.v1i2017.1837.

Moura V, Silva JPC, Rosell ECF, Alves WWA. 2017. Análise multitemporal do uso e ocupação do solo em Áreas de Preservação Permanente (APP) na bacia do rio Piranha, São Miguel do Guaporé, Rondônia (RO), Brasil. Revista Geográfica Venezolana, v. 58, n. 2, p. 414-429. Disponível em: https://www.redalyc.org/pdf/3477/347753793010.pdf. Acesso em 12/04/2020

Nóbrega RS. 2014. Impactos do desmatamento e de mudanças climáticas nos recursos hídricos na Amazônia ocidental utilizando o modelo SLURP. Revista Brasileira de Meteorologia, [s.l.], v. 29, n., p.111-120. http://dx.doi. $\operatorname{org} / 10.1590 / 0102-778620130024$. 
Oliveira IP, Santos KJG, Araujo AA, Oliveira LC. 2005. Queimadas e Suas Consequências na Região Centro Oeste. Faculdade Montes Belo, Goiás, v. 1, n. 2, p.88-103.

Paiva MC. 2014. Análise da Qualidade da Água de um Sistema de Piscicultura: Estudo de Caso no Município de Ji-Paraná / RO - Brasil. 90 f. TCC (Graduação) - Curso de Engenharia Ambiental, Departamento de Engenharia Ambiental, Universidade Federal de Rondônia, Ji-paraná, 2014. Disponível em: <http://www.engenhariaambiental.unir. br/uploads/65413365/arquivos/FINAL_FINAL____713769208.pdf>. Acesso em: 17 out. 2019.

Paula JM. 2008. KARO e IKÓLÓÉHJ: escola e seus modos de vida. Dissertação (Mestrado em Geografia): Fundação Universidade Federal de Rondônia UNIR, Porto Velho.

Rodrigues HV, Santos AM, Santos RF, Siqueira JAC, Villa B, Tokura LK, Lewandoski CF, Ganascini D. 2019. Análise da Qualidade Ambiental da Bacia Hidrográfica do Igarapé Dois de Abril, Ji-Paraná - RO. Almanaque Multidisciplinar de Pesquisa, S.l., v. 1, n. 2, p. 79-114. Disponível em: http://publicacoes.unigranrio.edu.br/index.php/amp/index. Acesso em: 06 abr. 2020.

Rosa R. 2005. Geotecnologias na Geografia Aplicada. Revista do Departamento de Geografia, Uberlândia, v. 16, p.8190.

Rosenback R, França AAS, Florenzano TG. 2005. Análise Comparativa dos dados NDVI obtidos de imagens CCD/CBERS e TM/ Landsat5 em uma área urbana. In: XII Simpósio Brasileiro De Sensoriamento Remoto, 2005, Goiânia. Anais... São José dos Campos: INPE, p.1075-1082. Disponível em: <http://marte.dpi.inpe.br/col/ltid.inpe.br/ sbsr/2004/11.16.17.49/doc/1075.pdf>. Acesso em: 31 de out. 2019.

Santos ASRM, Mauro TL, Souza LA, Senigalia RLC, Castro DA, Santos ES. 2019. Métodos de Classificação Supervisionada Aplicados no Uso e Ocupação do Solo no Município de Presidente Médice - RO. Biodiversidade, v.18, n.1, pág. 150-159. Disponível em: http://periodicoscientificos.ufmt.br/ojs/index.php/biodiversidade/article/view/8242.

Santos FA, Oliveira WAS. 2015. Aplicação do Índice de Vegetação por Diferença Normalizada (NDVI) para Avaliação da Cobertura Vegetal do Açude Caldeirão, em Piripiri (PI), Brasil. Revista Equador, [s.1.], v. 4, n. 2, p.114-127. Disponível em: <https://revistas.ufpi.br/index.php/equador/article/view/3408/2069>

Santos TA. 2018. Diagnóstico Ambiental e Modelagem Matemática Aplicada em Microbacias Urbanas no Município de Ji-Paraná (RO): subsídios ao enquadramento normativo. 2018. 79 f. TCC (Graduação) - Curso de Engenharia Ambiental, Universidade Federal de Rondônia, Ji-Paraná. Disponível em: http://www.gpeass.unir.br/uploads/29475343/ arquivos/TCC_Thiago_Santos_Turma_2014_174163980.pdf. Acesso em: 04 abr. 2020.

Silva DPP, Andrade NLR, Webler AD. 2019. Qualidade da água de nascentes urbanas: estudo de caso em microbacia Amazônica, município de Ji-Paraná/RO. Revista Ibero Americana de Ciências Ambientais, v.10, n.3, p.90-102. http:// doi.org/10.6008/CBPC2179-6858.2019.003.0009.

Silva MSGM, Losekann ME, Hisano H. 2013. Aquicultura: Manejo e Aproveitamento de Efluentes. Jaguariuna: Embrapa, 39 p. Disponível em: <https://www.infoteca.cnptia.embrapa.br/bitstream/doc/972692/1/Doc95.pdf>. Acesso em: 17 out. 2019

Silva RF. 2016. Análise dos impactos ambientais da Urbanização sobre os recursos hídricos na sub-bacia do Córrego Vargem Grande em Montes Claros-MG. Caderno de Geografia, [s.l.], v. 26, n. 47, p.966-978. http://dx.doi.org/10.5752/ p.2318-2962.2016v26n47p966.

Sobral MC, Lopes H, Candeias AL, Melo G, Gunkel G. 2017. Geotecnologias na gestão de reservatórios: uma revisão e uma proposta de integração: uma revisão e uma proposta de integração. Engenharia Sanitaria e Ambiental, [s.1.], v. 22, n. 5, p. 841-852. http://dx.doi.org/10.1590/s1413-41522017111054.

Sodré FF. 2012. Fontes Difusas de Poluição da Água: Características e métodos de controle. AQQUA, Brasília, v. 1, n. 1, p.9-16. Disponível em: <http://www.aqqua.unb.br/images/Artigos/Tematicos/difusa.pdf>. Acesso em: 30 out. 2019.

Souza LMG. 2017. Análise da Evolução do Desmatamento na Bacia do Rio Ipanema Através do Sensoriamento Remoto. 2017. 51 f. Dissertação (Mestrado) - Curso de Metereologia, Universidade Federal de Alagoas, Maceió. 
Souza MFM. 2014. O Saneamento Básico e Suas Implicações no Meio Ambiente e na Saúde Humana. 2014.41 f. Monografia (Especialização) - Curso de Gestão Ambiental, Universidade Tecnológica Federal do Paraná, Medianeira. Disponível em: <http://repositorio.roca.utfpr.edu.br/jspui/bitstream/1/4568/1/MD_GAMUNI_2014_2_55.pdf >.Acesso em: 30 out. 2019. 